\title{
A Research on Students' Preferences for Mobile On-Screen Keyboard
}

\author{
Mustafa Serkan Abdusselam \\ Assistant Professor, Department of CEIT, Faculty of Education \\ Giresun University, Giresun, Turkey \\ https://orcid.org/0000-0002-3253-7932
}

Manuscript ID:

EDU-2021-09023593

Volume: 9

Issue: 2

Month: March

Year: 2021

P-ISSN: 2320-2653

E-ISSN: 2582-1334

Received: 14.11.2020

Accepted: 08.01.2021

Published: 01.03.2021

\begin{abstract}
In recent years, growing technology has affected people's communication. Not only speaking and listening but also writing has an important role in communication. Particularly, devices have changed and applications have varied thanks to spreading mobile hardware. The aim of this study is to explore the usage status and preferences of students for mobile on-screen keyboards. In this regard, 20 common keyboard programs offered for IOS and Android platforms were examined. A question pool including various items about the features of these programs was created for the survey to be used. The developed survey consists of 27 items, 26 of which are three-point Likert types and one of which is semi-structured type. During the study, 238 participants completed the survey. Frequencies and percentages were calculated for the collected data, and participants ' preferences were determined. The results conclude that student mostly has used the keyboard for the WhatsApp application. While the most preferred features are local character support, frequently used words, voice message sending, vertical or horizontal usage, key response time, typing with swipe keyboard was the least preferred one by the participants.
\end{abstract}

Keywords: Mobile platform, On-screen keyboard, Preferences, Student, Keyboard usage

\section{Introduction}

Communication (Latin: "commūnicāre") has taken its place in many languages in terms of its origin as it used to be. According to the Turkish Language Institution Dictionary (2018), communication is the transfer of emotions, information to others' thoughts in every conceivable way. Although the forms and channels of communication have changed, people have used

Citation:

Abdusselam, Mustafa

Serkan. "A Research on

Students' Preferences

for Mobile On-Screen

Keyboard." Shanlax

International Journal of

Education, vol. 9, no. 2,

2021, pp. 46-53.

DOI:

https://doi.org/10.34293/ education.v9i2.3593 communication in agreement with their environment and express themselves. Since they have spent most of their daily life through communication-based activities, they have tried to develop this communication skill and use it effectively (Küçük et al., 2012). At the beginning of humanity, people tried to express themselves with primitive drawings on the cave walls, and over the years, they gave abstract meanings to the drawings instead of concrete (Çeken et al., 2017). However, the writing methods that had taken their place in many cultures in the early ages gave birth to today's alphabets (Kayıran \& Metintaş, 2009).

Sharing, protecting and transferring the peoples' knowledge to the next generation get easier through the alphabet. Yet, with the differentiation of generations, their preferences have varied in terms of their priorities. Unlike previous generations, the new one, namely digital natives, who are considered to be born after the eighties, having a culture that grows in digital technology, creates and shares online content, is prone to sharing information in virtual environments (Prensky, 2009). Particularly, they can continue to communicate by making large numbers of friends on social networking sites (Gasser et al., 2012; Jukes et al., 2010; Palfrey \& Gasser, 200). This generation has been the subject of many studies regarding their use of digital technology $(\mathrm{Ng}, 2012)$. 
According to the usage of information and communications technology (ICT) research in 2018, the proportion of individuals using the internet rose to $72.9 \%$, whereas the percentage of people using the computer was $59.6 \%$ in Turkey. Additionally, the rate of computers in households was $10 \%$ in 2004 and this rate increased to $28.4 \%$ in 2018 . On the other hand, the percentage of mobile phone/ smartphone usage sharply increased from $53.7 \%$ in 2004 to $98.7 \%$ in 2018. It was found that households use the internet almost every day (88.6\%) and the highest rate among the purposes of internet use is the use of social media (84.1\%) and this usage is mostly seen in the 16-24 age group (www.tuik.gov.tr, 2019). Also, the Internet is not only used for social media networks and online access services to communicate with friends and families but also to download music and video files (Ito et al. 2008). Nowadays, young people mostly use information technology by interacting with tablets and mobile phones. These information technologies, which have a touch screen, often have on-screen keyboards instead of a mechanical keyboard (Baştuğ \& Keskin, 2017). Young people's use of social media technologies has increased through these devices and they use these on-screen keyboards to produce and communicate content (Bulduklu \& Özer, 2016).

Certainly, enriching our environment with many digital types of equipment will increase the interaction of users with these devices. When this interaction is examined in terms of humancomputer interaction, touch screens with on-screen keyboards will be in the foreground since it is one of the most prominent among interactive devices. In this context, when examining the most used platforms in the mobile environment, it can be said that the on-screen keyboards offered to the users are represented with a different design. Figure 1 shows both on-screen keyboards used on Android and iOS mobile platforms. In case the Turkish language is selected during the examination of the screen keyboards of both platforms, the so-called mini-QWERTY keyboard is used, which is common in English-speaking countries, and is reduced to small dimensions based on the Q keyboard, which is the typewriter keyboard standard. However, in the notation of the letters belonging to the Turkish language, they differed.
$\begin{array}{llllllllll}1 & 2 & 3 & 4 & 5 & 6 & 7 & 8 & 9 & 0\end{array}$

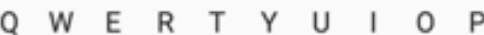

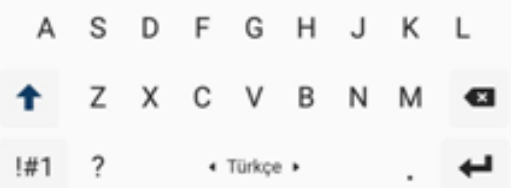

Figure 1: a. On-Screen Keyboard (Android)

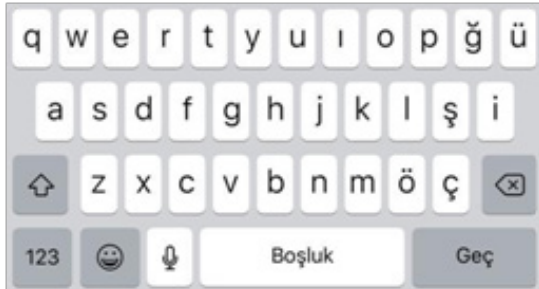

Figure 1: b. On-Screen Keyboard (IOS)

\section{Review of Literature}

In the literature review, there are several studies conducted on used on-screen keyboards in mobile platforms. Some of them are focus on problems of design (Bi et al., 2012; Sears, 1991), improve typing methods (Findlater et al., 2012), make typing easier by using a fish-eye view (Pollmann et al., 2014) and allow typing from different angles (Sears et al., 1993; Coleman et al., 1991), or classify input hand postures (Yin et al., 2013) to optimize on-screen keyboards (Smith et al., 2015) and improving automatic adaptation (Findlater \& Wobbrock, 2012), and others are focus on user experience (Reyal et al., 2015). In this age, digital hardware is becoming widely used and its use also is increasing dramatically. As a result, touch screens will become more widespread, and usage of on-screen keyboards in these screens will be diversified. In determining the technical framework of the on-screen keyboards it is important to know the expectations of users of the on-screen keyboards. Thus, user-friendly interfaces could be created and the computer-human interaction could be kept at the highest level. Also, the newly designed screen will demonstrate a more effective use in all areas where on-screen keyboards are used. It was found that there is no research that directly deals with the users' preferences of on-screen keyboards used in mobile platforms. In this context, it is thought that the study will contribute to the literature by examining 
the mobile screen keyboards in terms of users' preferences. As a result, this study is important, as it will determine the features that should be found on an optimum on-screen keyboard by evaluating users' preferences.

The aim of this research is to reveal the preferences of students using on-screen keyboards for mobile devices. In this context, the frame of on-screen keyboards and user expectations will be revealed. In line with the purpose of the research, the main question is what those young individuals pay attention to or prefer in on-screen keyboards used in mobile platforms. The sub-questions of the research are as follows:

1. What are the mobile operating system preferences of students?

2. When they obtained the first mobile phone?

3. Which application used by participants in written communication?

4. What are the students' preferences regarding onscreen keyboards on mobile platforms?

\section{Materials and Methods}

The scope of this research consists of the usage of on-screen keyboards in the communication of young people on mobile platforms and their application preferences. The survey method used in many studies to determine the preferences of individuals (Zhu \& Cho, 2018; Durmuş \& Battal, 2018), within this scope, this method was used in conducting the research. A conceptual framework of this study was formed through a literature review and a questionnaire was used to determine the views of young individuals.

\section{The Study Group}

A face-to-face survey was conducted in the spring semester of the 2018-2019 academic year with a sample of 238 high school and university students who are volunteers in Giresun province. The heterogeneity of the study was increased by selecting students from different fields for the sample group. In this context, $70 \%(\mathrm{n}=167)$ males and 30\% $(\mathrm{n}=71)$ females students were contributed to the study. It was determined that $39 \%(n=93)$ of the participants were social, $31 \%(\mathrm{n}=73)$ were science and $30 \%$ were equally-weighted. $58 \%(n=137)$ of these students study at university and $42 \%(n=101)$ study at high school.

\section{Data Collection Instruments}

The outlines of the data collection instrument were determined by literature review and analysis of top the ten on-screen keyboards of common and most preferred ones on Android and IOS platforms markets. The on-screen keyboards included in the research are Tambu, Gboard, ai. Type, SwiftKey, GoKeyboard, Flesky, Swype, Minuum, Gboard, TouchPal, and Kika Keyboard. All the features of these 10 keyboards are listed and listed in the items pool. The questionnaire was developed using these items pool. The questionnaire examined by an expert became ready for a survey after necessary corrections. In the first review, the items which are related to the features of the installed application and not related to the typing of the on-screen keyboard in the application used were ignored and removed. The pilot study of the research was carried out with 26 structured items were related to the features that the user paid attention to on the mobile screen keyboard and one of which is the semi-structured type. The survey was applied to 22 young volunteer participants. In line with the findings, the scope of some items has been expanded.

\section{Data Analysis}

The questionnaire used in the research contains two main sections. One on the demographic information of participants and one on the features of the mobile on-screen keyboard are tested by participants. As demographic features, gender, age, the brand of the smartphone used, the age when they had their first phone, and most frequently preferred correspondence application were examined. The questionnaire was prepared as in the triple Likert rating scale (yes $=3$, partially $=2$, no $=1$ type). The data obtained within the research scope was analyzed by using SPSS v.22 programs and the reliability of the survey was .773. Percentage, frequency, standard deviation, and arithmetic mean values were calculated. As a result of these calculations, the range of evaluation points taken into consideration in the range of widths was determined as 1.00-1.66 no, 1.67-2.32 partially, and 2.33-3.00 yes. 
Results and Discussion

In the first part, where the demographic characteristics of the research questionnaire were analyzed, it was found that the age range of participants was between 16 and 24 years. Graph 1 shows the distribution of participants by gender and preferred operating system. Overall, the amount of participants using Android is over three times as much as IOS users. However, the rates of male and female users in both pie graphs are approximately the same.

The overall distribution of men and females is $70 \%$ to $30 \%$, android mobile operating system usage distributions to $72 \%$ to $28 \%$, and iOS mobile operating system used to $63 \%$ to $37 \%$.

Figure 2 illustrates the age range of obtaining the first mobile phone.In general, mobile phone ownership occurs at most between the ages of 13 and 14. At the same time, the age of owning the mobile phone started at the age of eight. Also, the rate of obtaining mobile phone stead increase with age and peaked when the participants turn 13 or 14 . However, year by year, owning a mobile phone rate gradually declined.

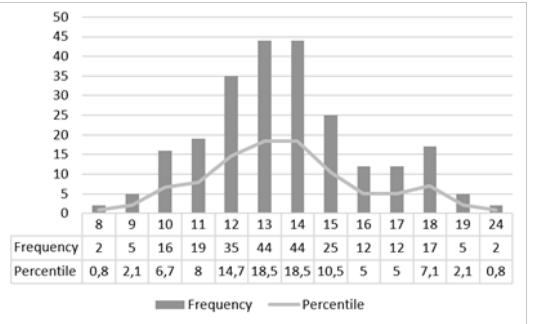

Figure 2: Lines of Participants Obtained First Mobile Phone

The percentage of mobile phone brands used by participants are Samsung, iPhone, General Mobile, Huawei, LG, Asus, Sony, Casper, HTC, Vestel,
Lenova $(47 \%, 21 \%, 6 \%, 6 \%, 5 \%, 3 \%, 3 \%, 3 \%$, $2 \%, 2 \%, 2 \%$ respectively) and $1 \%$ by the other brands (Xiaomi, Motorola and Nokia). Figure 3 demonstrates the distribution of applications used by participants in texting by mobile phones. Generally, WhatsApp (83\%) is the most popular application among all the participants, followed by SMS with $11 \%$. Messenger is similar to $\mathrm{BiP}$ in that their rates are about $2 \%$, and also usage of Skype is similar to that of Instagram (1\%).

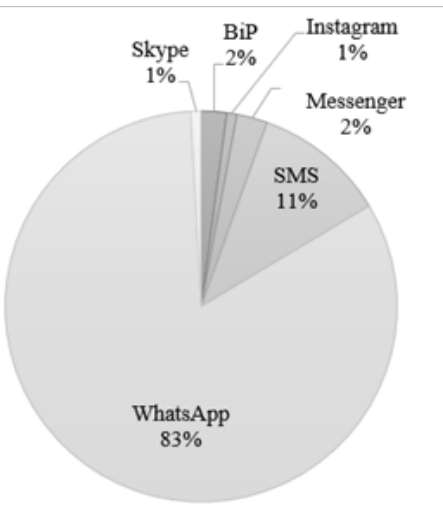

\section{Figure 3: Distribution of Application Used by Participants in Written}

The second part of the questionnaire with the features of the mobile on-screen keyboard is responded to by participants. Table 1 presents 26 items, the results obtained from the mean (x), and the standard deviations (SS). The value of the mean range is from 1.51 to 2.69. The least attention feature is swiping. Besides, the participants partially pay attention to 17 features. Moreover, the most important features are the fast response time of the keys, local character support (like $\breve{g}, \ddot{u}, s ̧, o ̈, c ̧$ ), adding favorites, emoji, sending voice messages, horizontal / vertical used, and the last one is attachment properties.

Table 1: Distribution of User Response on Features of On-Screen Keyboards Scale

\begin{tabular}{|l|c|c|c|c|c|c|c|c|c|c|c|c|}
\hline \multirow{2}{*}{ Item } & \multicolumn{2}{|c|}{ Yes } & \multicolumn{2}{|c|}{ Partially } & \multicolumn{2}{|c|}{ No } & \multicolumn{2}{c|}{ Gender } & \multicolumn{2}{c|}{ Platform } & $\overline{\mathrm{x}}$ & SS \\
\cline { 2 - 14 } & $\mathbf{f}$ & $\mathbf{\%}$ & $\mathbf{f}$ & $\mathbf{\%}$ & $\mathbf{f}$ & $\mathbf{\%}$ & Male & Female & Android & IOS & & \\
\hline $\begin{array}{l}\text { 1-I prefer wider button } \\
\text { range }\end{array}$ & 122 & 51 & 32 & 14 & 84 & 35 & 2,08 & 2,35 & 2,20 & 2,00 & 2,16 & 0,918 \\
\hline $\begin{array}{l}\text { 2-I prefer the keyboard } \\
\text { with Turkish Characters }\end{array}$ & 193 & 81 & 12 & 5 & 33 & 14 & 2,65 & 2,72 & 2,63 & 2,82 & 2,67 & 0,707 \\
\hline $\begin{array}{l}\text { 3-I prefer using the } \\
\text { word completion feature }\end{array}$ & 138 & 58 & 17 & 7 & 83 & 35 & 2,19 & 2,32 & 2,24 & 2,20 & 2,23 & 0,937 \\
\hline
\end{tabular}




\begin{tabular}{|c|c|c|c|c|c|c|c|c|c|c|c|c|}
\hline $\begin{array}{l}\text { 4-I pay attention to the } \\
\text { keyboard's frequently } \\
\text { used (emoji, word, etc.) } \\
\text { section }\end{array}$ & 182 & 77 & 8 & 3 & 48 & 20 & 2,49 & 2,75 & 2,54 & 2,65 & 2,56 & 0,808 \\
\hline $\begin{array}{l}\text { 5-I prefer writing with } \\
\text { swipe method }\end{array}$ & 45 & 19 & 34 & 14 & 159 & 67 & 1,51 & 1,55 & 1,54 & 1,43 & 1,52 & 0,794 \\
\hline $\begin{array}{l}\text { 6-I pay attention to the } \\
\text { keyboard's punctuation } \\
\text { checker feature }\end{array}$ & 109 & 46 & 19 & 8 & 110 & 46 & 1,96 & 2,08 & 1,97 & 2,10 & 2,00 & 0,961 \\
\hline $\begin{array}{l}\text { 7-I prefer the keyboard } \\
\text { with different themes }\end{array}$ & 100 & 42 & 36 & 15 & 102 & 43 & 2,01 & 1,94 & 2,01 & 1,94 & 1,99 & 0,923 \\
\hline $\begin{array}{l}\text { 8-I prefer keyboard with } \\
\text { a fast response time }\end{array}$ & 196 & 82 & 10 & 4 & 32 & 14 & 2,63 & 2,83 & 2,69 & 2,69 & 2,69 & 0,697 \\
\hline $\begin{array}{l}\text { 9-I prefer keyboard with } \\
\text { Emoji }\end{array}$ & 179 & 75 & 7 & 3 & 52 & 22 & 2,44 & 2,75 & 2,51 & 2,63 & 2,53 & 0,830 \\
\hline $\begin{array}{l}\text { 10-I prefer keyboard } \\
\text { with language } \\
\text { translation }\end{array}$ & 141 & 59 & 28 & 12 & 69 & 29 & 2,34 & 2,23 & 2,33 & 2,18 & 2,30 & 0,891 \\
\hline $\begin{array}{l}\text { 11-I prefer keyboard } \\
\text { with concise words } \\
\text { (proverb) }\end{array}$ & 67 & 28 & 36 & 15 & 135 & 57 & 1,72 & 1,70 & 1,69 & 1,82 & 1,71 & 0,878 \\
\hline $\begin{array}{l}\text { 12-I prefer keyboard } \\
\text { with share location }\end{array}$ & 99 & 42 & 26 & 11 & 113 & 47 & 1,86 & 2,13 & 1,94 & 1,94 & 1,94 & 0,944 \\
\hline $\begin{array}{l}\text { 13-I prefer keyboard } \\
\text { with speech recognition }\end{array}$ & 138 & 58 & 25 & 11 & 75 & 31 & 2,25 & 2,31 & 2,22 & 2,43 & 2,26 & 0,910 \\
\hline $\begin{array}{l}\text { 14-I prefer keyboard } \\
\text { finished the sentence } \\
\text { instead of me }\end{array}$ & 115 & 48 & 19 & 8 & 104 & 44 & 2,01 & 2,13 & 2,11 & 1,82 & 2,05 & 0,960 \\
\hline $\begin{array}{l}\text { 15-I prefer keyboard } \\
\text { with calculator }\end{array}$ & 73 & 31 & 38 & 16 & 127 & 53 & 1,78 & 1,76 & 1,76 & 1,82 & 1,77 & 0,890 \\
\hline $\begin{array}{l}\text { 16-I pay attention to } \\
\text { keyboard changeable } \\
\text { layout }\end{array}$ & 102 & 43 & 22 & 9 & 114 & 48 & 1,96 & 1,92 & 1,93 & 2,04 & 1,95 & 0,953 \\
\hline $\begin{array}{l}\text { 17-I pay attention to } \\
\text { keyboard changeable } \\
\text { size }\end{array}$ & 104 & 44 & 22 & 9 & 112 & 47 & 1,91 & 2,10 & 1,92 & 2,14 & 1,97 & 0,954 \\
\hline $\begin{array}{l}\text { 18-I prefer keyboard } \\
\text { with writing numbers on } \\
\text { written letter }\end{array}$ & 130 & 55 & 22 & 9 & 86 & 36 & 2,26 & 2,00 & 2,20 & 2,12 & 2,18 & 0,937 \\
\hline $\begin{array}{l}\text { 19-I pay attention } \\
\text { to feature adding } \\
\text { automatically spaces } \\
\text { between words in a text }\end{array}$ & 139 & 59 & 16 & 6 & 83 & 35 & 2,16 & 2,41 & 2,19 & 2,41 & 2,24 & 0,939 \\
\hline $\begin{array}{l}\text { 20-I pay attention to } \\
\text { adding files (image, text } \\
\text { etc.) feature }\end{array}$ & 153 & 64 & 21 & 9 & 64 & 27 & 2,34 & 2,46 & 2,31 & 2,61 & 2,37 & 0,880 \\
\hline
\end{tabular}




\begin{tabular}{|l|l|l|l|l|l|l|l|l|l|l|l|l|}
\hline $\begin{array}{l}\text { 21-I pay attention to } \\
\text { keyboard prices }\end{array}$ & 145 & 61 & 20 & 8 & 73 & 31 & 2,25 & 2,42 & 2,25 & 2,51 & 2,30 & 0,910 \\
\hline $\begin{array}{l}\text { 22-I pay attention to } \\
\text { sending voice messages } \\
\text { feature }\end{array}$ & 172 & 72 & 16 & 7 & 50 & 21 & 2,46 & 2,65 & 2,49 & 2,61 & 2,51 & 0,820 \\
\hline $\begin{array}{l}\text { 23-I pay attention to } \\
\text { keyboard browser } \\
\text { support feature }\end{array}$ & 116 & 49 & 33 & 14 & 89 & 37 & 2,11 & 2,13 & 2,13 & 2,06 & 2,11 & 0,923 \\
\hline $\begin{array}{l}\text { 24-I pay attention to } \\
\text { keyboard horizontal / } \\
\text { vertical usage }\end{array}$ & 155 & 65 & 21 & 9 & 62 & 26 & 2,38 & 2,42 & 2,35 & 2,53 & 2,39 & 0,873 \\
\hline $\begin{array}{l}\text { 25-I pay attention } \\
\text { to keyboard camera } \\
\text { support feature }\end{array}$ & 122 & 51 & 32 & 14 & 84 & 35 & 2,10 & 2,31 & 2,11 & 2,35 & 2,16 & 0,918 \\
\hline $\begin{array}{l}\text { 26-I pay attention to } \\
\text { keyboard social media } \\
\text { support feature }\end{array}$ & 132 & 56 & 35 & 14 & 71 & 30 & 2,20 & 2,39 & 2,24 & 2,31 & 2,26 & 0,889 \\
\hline
\end{tabular}

In terms of gender, females' mean values were higher than those of males' regarding a range of buttons, adding a space between words, keyboard prices and sharing of posts (on social media) properties. Conversely, males' mean values were higher just for the language translation feature.

Conforming to the operating system used, IOS users' mean values were over than those of Android users' depending on the ability to write what is spoken, adding a space between the words, keyboard prices, and camera support. In contrast, Android users' mean values were higher only for the language translation feature.

\section{Research Gap and Conclusion}

Within the scope of the research, an overwhelming majority of participants prefer Android to other operating systems. This usage is also common in the world as seen in Divya and Kumar's (2016) research study. Besides, students mostly have used WhatsApp application for texting. Where Seufert et al. (2016) claim that WhatsApp is one of the most commonly used applications in communication, especially in chatting and file transfer (Jadhav et al., 2013). Moreover, the features that users pay attention to the on-screen keyboard feature could be examined under two headings.

Firstly, giving the users a sense of reality in the on-screen keyboard is not physical hardware. According to AbuHmed et al. (2015), the dimensional characteristics of the on-screen keyboards affect the user's performance because a few errors could be made on small screen keyboards. Therefore, onscreen keyboard developers should design mobile screen keyboards in the most ergonomic way by considering the dimensional characteristics. It should be noted that on-screen keyboards would constantly compete with the mechanical ones. As to the cause, Debue et al.(2018) stated that more mental effort is required than mechanical keyboards while on-screen keyboards are being used. In this context, on-screen keyboards should be as successful as possible to give a sense of reality, such as the high speed of the keys' response, fixable width of the button range and changeable button layout.

On the other hand, we should not ignore the advantages of an on-screen keyboard compared to the mechanical alternatives; using frequently used words, sending emoji and voice messages, using horizontally or vertically, support their language which these are the high attention paid by the student. However, the least attention is the ability to scroll with finger gestures (swiping). All these advantages or conveniences are intended to minimize muscle activity when the user taps on buttons. This can be explained by Chang et al. (2017) that button positions on the on-screen keyboard affect muscle activity, touch times and usage habits. However, although swiping was developed to provide this kind of convenience, students hardly see this feature as a 
criterion and do not prefer it. With these results, onscreen keyboard developers can use this information in their next design planning.

Secondly, contributing to the literature, this research shows similarities from the standpoint of some of the features that male and female users preferences to the on-screen keyboard. While female users and IOS operating system users are similar in pay attention to the on-screen keyboard features that are about adding a space between the words and keyboard prices, male users and Android operating system users are both similar in considering, namely language translation. These results are useful for keyboard developers in marketing a keyboard and determining the target audience.

The feature that young people prefer using onscreen keyboards; may vary depending on the changing needs of the generation, the hardware and operating system used, or the user's gender. To investigate this change, it is recommended that this research be carried out periodically.

\section{References}

AbuHmed, Tamer, et al. "UOIT Keyboard: A Constructive Keyboard for Small Touchscreen Devices." IEEE Transactions on HumanMachine Systems, vol. 45, 2015, pp. 782-789.

Baştuğ, Muhammet, and Hasan Kağan Keskin. "Reliabilty and Validity Study of Scale Attitudes towards Writing from Paper to Digital." Educational Technology Theory and Practice, vol. 7, no. 2, 2017, pp. 58-72.

$\mathrm{Bi}$, Xiaojun, et al. "Multilingual Touchscreen Keyboard Design and Optimization." HumanComputer Interaction, vol. 27, no. 4, 2012, pp. 352-382.

Bulduklu, Yasin, and Nuri Paşa Özer. "Young People's Smart Phone Use Motivations." Itobiad: Journal of the Human \& Social Science Researches, vol. 5, no. 8, 2016, pp. 2963-2986.

Çeken, Birsen, et al. "Use and Examination of Emojis in Communication." 21. Yüzyılda Eğitim Ve Toplum Eğitim Bilimleri Ve Sosyal Araştırmalar Dergisi, 2017, pp. 91-106.

Chang, Joonho, et al. "Effects of Button Position on a Soft Keyboard: Muscle Activity, Touch
Time, and Discomfort in Two-thumb Text Entry." Applied Ergonomics, vol. 60, 2017, pp. 282-292.

Chang, Joonho, et al. "Effects of Button Position on a Soft Keyboard: Muscle Activity, Touch Time, and Discomfort in Two-thumb Text Entry." Applied Ergonomics, vol. 60, 2017, pp. 282-292.

Coleman, Marilyn F., et al. "User Performance on Typing Tasks Involving Reduced-Size, Touch Screen Keyboards." Vehicle Navigation and Information Systems Conference, 1991.

Debue, Nicolas, et al. "Comparative Study of Laptops and Touch-Screen PCs for Searching on the Web." International Conference on Engineering Psychology and Cognitive Ergonomics, 2018, pp. 403-418.

Divya, K., and Venkata Krishna Kumar. "Comparative Analysis of Smart Phone Operating Systems Android, Apple iOS and Windows." International Journal of Scientific Engineering and Applied Science, vol. 2, no. 2, 2016, pp. 432-438.

Durmuş, İbrahim, and Fetullah Battal. "University Students Purchases Attitude toward Advertising and Brand Preferences." Gümüşhane Üniversitesi Sosyal Bilimler Enstitüsü Elektronik Dergisi, vol. 9, 2018, pp. 147-176.

Findlater, Leah, and Jacob Wobbrock. "Personalized Input: Improving Ten-finger Touchscreen Typing through Automatic Adaptation." Proceedings of the SIGCHI Conference on Human Factors in Computing Systems, 2012, pp. 815-824

Findlater, Leah, et al. "Beyond QWERTY: Augmenting Touch-Screen Keyboards with Multi-Touch Gestures for Non-Alphanumeric Input." CHI, 2012, pp. 2679-2682.

Gasser, Urs, et al. Youth and Digital Media: From Credibility to Information Quality, Berkman Center Research Publicatio, 2012.

Ito, Mizuko, et al. Living and Learning with New Media: Summary of Findings from the Digital Youth Project. The MIT Press, 2009.

Jadhav, Dhiraj, et al. "Usability Evaluation of Messenger Applications for Android Phones 
using Cognitive Walkthrough." Proceedings of the 11th Asia Pacific Conference on Computer Human Interaction, 2013.

Jukes, Ian, et al. Understanding the Digital Generation: Teaching and Learning in the New Digital Landscape. Corwin Press, 2010.

Kayıran, Mehmet, and Yahya Metintaş. "Transition Period to New Turkish Alphabet Originating from Latin Alphabet and National Schools." Dumlupinar Üniversitesi Sosyal Bilimler Dergisi, 2009.

Küçük, Mestan, et al. "İletişim Kavramı ve Iletişim Süreci." Iletişim Bilgisi, Anadolu Üniversitesi Yayınları, 2012, pp. 2-19.

Ng, Wan. "Can We Teach Digital Natives Digital Literacy?." Computers \& Education, vol. 59, no. 3, 2012, pp. 1065-1078.

Palfrey, John, and Urs Gasser. Born Digital: Understanding the First Generation of Digital Natives. ReadHowYouWant.com, 2011.

Pollmann, Frederic, et al. "HoverZoom: Making Onscreen Keyboards More Accessible." CHI'14 Extended Abstracts on Human Factors in Computing Systems, 2014, pp. 1261-1266.

Prensky, Marc. "H. Sapiens Digital: From Digital Immigrants and Digital Natives to Digital Wisdom." Innovate: Journal of Online Education, vol. 5, no. 3, 2009.
Reyal, Shyam, et al. "Performance and User Experience of Touchscreen and Gesture Keyboards in a Lab Setting and in the Wild." Proceedings of the 33rd Annual ACM Conference on Human Factors in Computing Systems, 2015, pp. 679-688.

Sears, Andrew. "Improving Touchscreen Keyboards: Design Issues and a Comparison with Other Devices." Interacting with computers, vol. 3, no. 3, 1991, pp. 253-269.

Seufert, Michael, etal. "Group-based Communication in WhatsApp." 2016 IFIP networking conference (IFIP networking) and workshops, 2016.

Smith, Brian A., et al. "Optimizing Touchscreen Keyboards for Gesture Typing." Proceedings of the 33rd Annual ACM Conference on Human Factors in Computing Systems, 2015, pp. 3365-3374.

Yin, Ying, et al. "Making Touchscreen Keyboards Adaptive to Keys, Hand Postures, and Individuals - A Hierarchical Spatial Backoff Model Approach.” CHI, 2013, pp. 2775-2784.

Zhu, Xiaohua, and Moonhee Cho. "The End of Ownership?: An Investigation of Users' Preferences and Perceptions of Ownership Configurations." Proceedings of the Association for Information Science and Technology, vol. 55, no. 1, 2018, pp. 618-627.

\section{Author Details}

Mustafa Serkan Abdusselam, Assistant Professor, Department of CEIT, Faculty of Education, Giresun University, Giresun, Turkey, Email ID: mustafa.serkan@giresun.edu.tr 